Chapman University

Chapman University Digital Commons

ESI Publications

Economic Science Institute

2009

\title{
Recordkeeping Alters Economic History by Promoting Reciprocity
}

Sudipta Basu

Temple University

John Dickhaut

Chapman University

Gary Hecht

Emory University

Kristy Towry

Emory University

Gregory Waymire

Emory University

Follow this and additional works at: http://digitalcommons.chapman.edu/esi_pubs

Part of the Economic Theory Commons, and the Other Economics Commons

\section{Recommended Citation}

Basu, S., Dickhaut, J., Hecht, G., Towry, K., and Waymire, G. "Recordkeeping Alters Economic History by Promoting Reciprocity." Proceedings of the National Academy of Sciences of the United States of America, 106 (4), pp. 1009-1014, January, 2009.

DOI: $10.1073 /$ pnas.0811967106

This Article is brought to you for free and open access by the Economic Science Institute at Chapman University Digital Commons. It has been accepted for inclusion in ESI Publications by an authorized administrator of Chapman University Digital Commons. For more information, please contact laughtin@chapman.edu. 


\section{Recordkeeping Alters Economic History by Promoting Reciprocity}

\section{Comments}

This article was originally published in Proceedings of the National Academy of Sciences of the United States of America, volume 106, issue 4, in 2009. DOI: 10.1073/pnas.0811967106

\section{Copyright}

National Academy of Sciences 


\title{
Recordkeeping alters economic history by promoting reciprocity
}

\author{
Sudipta Basua , John Dickhaut ${ }^{b}$, Gary Hecht ${ }^{c}, K^{2}$ risty Towryc, and Gregory Waymire ${ }^{c, 1}$
}

${ }^{a}$ Fox School of Business and Management, Temple University, 1810 North 13th Street, Philadelphia, PA 19122; beconomic Science Institute and Argyros School of Business, Chapman University, One University Drive, Orange, CA 92866; and 'Goizueta Business School, Emory University, 1300 Clifton Road NE, Atlanta, GA 30322

Communicated by Vernon L. Smith, George Mason University, Fairfax, VA, December 3, 2008 (received for review November 8, 2007)

\begin{abstract}
We experimentally demonstrate a causal link between recordkeeping and reciprocal exchange. Recordkeeping improves memory of past interactions in a complex exchange environment, which promotes reputation formation and decision coordination. Economies with recordkeeping exhibit a beneficially altered economic history where the risks of exchanging with strangers are substantially lessened. Our findings are consistent with prior assertions that complex and extensive reciprocity requires sophisticated memory to store information on past transactions. We offer insights on this research by scientifically demonstrating that reciprocity can be facilitated by information storage external to the brain. This is consistent with the archaeological record, which suggests that prehistoric transaction records and the invention of writing for recordkeeping were linked to increased complexity in human interaction.
\end{abstract}

accounting | economic institutions | trust | memory | image score

Q uid pro quo behavior-that is, reciprocating behavior in kind-is present in all human moral codes (1-4). The evaluation, memory, and communication functions of the human brain promote exchange at a scale far greater than that of other primates (5). Humans identify and remember cheaters and verbally communicate knowledge of cheating to third parties (6, 7). Punishing norm violations or avoiding people with a reputation for cheating sustains reciprocity $(8-18)$.

But can the human brain alone provide a complete explanation for how memory enables more complex forms of reciprocal exchange among humans? The unaided human neocortex is constrained in sustaining social exchange in interactions that are complex, numerous, and heterogeneous (19). Yet, casual observation suggests that human economic institutions bind complete strangers together in vast networks of interaction known as "organizations" and "markets." For example, eBay employs thousands to operate global electronic markets that are used by millions of people (20). eBay participants likely trust that a proposed transaction can be completed on mutually beneficial terms in part because of eBay's extensive database of individual trading histories (a form of recordkeeping). These records of past transaction histories can allow reputations for trustworthiness to form, with the ultimate result that sellers with favorable histories receive higher prices $(21,22)$.

Computerized recordkeeping in online markets is the latest step in a long technological history. Humans have created and stored transactional records outside their brains for at least 10,000 years (23). Archaeologists have discovered nonwritten transactional artifacts that date to $8,000 \mathrm{BCE}$ and have documented that the independent invention of writing by the Sumerians (ca 3,200 BCE) was for keeping records $(24,25)$. Both of these innovations appeared concurrently with scale expansions in human settlements. Anthropologists demonstrate that symbolic artifacts serving a memory function are often a central feature of complex exchange in primitive societies (26). Scholars have suggested that the recordkeeping of modern accounting provides just such a memory aid $(27,28)$. This evidence suggests the possibility that recordkeeping is a culturally evolved institu- tion that complements the brain's ability to recall noncooperative behaviors and sustains reciprocal exchange in larger, morecomplex groups (29-31).

Economists have long recognized the central role of exchange, but have no scientific explanation and evidence for whether and how recordkeeping promotes reciprocity (32). We posit that recordkeeping helps foster reciprocity in complex settings where neuronal memory is implicitly taxed. The archaeological evidence noted above and the ubiquity of the receipt in developed economies suggests this is plausible (33). We test several hypotheses about the relation between exchange and recordkeeping by using a repeated trust game experiment (34-36). Our experimental design allows us to directly test whether the possibility of keeping records alters individual behavior and leads to differences in reputation formation, decision coordination, and economic histories.

\section{Experimental Design}

We conducted an experiment, in which we varied both the complexity of economic exchange and the availability of recordkeeping, to examine the role of recordkeeping in shaping an economy's history of reciprocal exchange. A single-dyad trust game pairs one investor anonymously with one trustee (34-36). In each period, the investor receives 10 units of experimental currency, which are referred to as lira, and decides how many lira of the 10 (in whole numbers) to send to the trustee. This investment generates gains because it is tripled en route to the trustee. The trustee then decides how much of the amount received to send back to the investor. The investor's return is thus determined by the trustee's decision. A large body of experimental evidence shows that, even in one-shot play, investors tend to make positive investments and trustees tend to reciprocate by sending back amounts that provide a positive net return to the investor $(37,38)$.

To capture complexity of economic exchange, the single-dyad trust game is extended to a multi-dyad trust game. In the multi-dyad economy, each subject simultaneously plays a trust game with 5 different trading partners. Every investor has 5 separate endowments of 10 lira, one for each trustee. For each 10-lira endowment, the investor decides how much of that amount to send to the respective trustee. Each trustee receives 5 tripled amounts, one from each of the 5 investors. Every trustee then decides, for each investor, how much of the amount received to send back.

We ran both the multi-dyad and single-dyad trust games for two types of economies: one in which subjects could choose to keep records and one in which recordkeeping was not possible.

Author contributions: S.B., J.D., G.H., K.T., and G.W. designed research, performed research, analyzed data, and wrote the paper.

The authors declare no conflict of interest.

Freely available online through the PNAS open access option.

${ }^{1}$ To whom correspondence should be addressed. E-mail: gregory_waymire@bus.emory.edu.

This article contains supporting information online at www.pnas.org/cgi/content/full/ 0811967106/DCSupplemental.

๑ 2009 by The National Academy of Sciences of the USA 
We implemented a repeated game by repeating the single-period game 10 times with new endowments of 10 lira each time (36). Repeated interaction allows a sequential history of exchange to unfold wherein subjects can condition their choices on the memory of past outcomes. Memory of past outcomes can also be used to evaluate the effectiveness of choices in light of partners' responses.

A key feature of our design is that records were kept only when a subject had access to the recordkeeping technology and chose to use it. When recordkeeping was available, $78 \%$ of subjects in the multi-dyad condition kept records compared with $50 \%$ in the single-dyad condition; this effect starts in the first period of play (see $S I)$. This evidence is consistent with our expectation that greater cognitive demands in the multi-dyad condition manifest themselves in increased use of the recordkeeping technology. We turn now to our major findings, which pertain to the multi-dyad economies; specifically, that the possibility of recordkeeping alters economic agents' memories and behaviors, thus creating different economic histories. Accordingly, we omit further discussion of the single-dyad economies (see $S I$ ).

\section{Hypotheses and Data Analysis}

In a multi-dyad setting, we expect that trading partners can better acquire and sustain reputations for trustworthy behavior with recordkeeping than without because it improves recall of past interactions. Reputation is an unobservable construct denoting an individual's beliefs about the expected behavior of a trading partner. For example, if a trustee earns a reputation for trustworthiness in the investor's mind, the investor will expect the trustee to reciprocate a large investment by providing a positive net return to the investor. The trustee's reputation will be built on what the investor recalls of previous interactions with that trustee. If recordkeeping promotes more effective recall of the past, it will promote reputation formation and result in increased coordination of trading partners' behavior (i.e., greater reciprocity). Thus, a different history of exchange decisions between the partners will emerge. We develop each hypothesis as we present our findings in the following subsections.

Recordkeeping Promotes Reputation Formation. Our first hypothesis is that improved memory from recordkeeping promotes reputation formation. As noted above, reputation refers to an individual's unobservable beliefs about a trading partner's likely behavior. Observing an individual's behavior leads to beliefs that constitute that individual's reputation. Because recordkeeping allows subjects to better recall partners' past decisions, we expect subjects in a recordkeeping economy will be able to form clearer mental categorizations of specific partners' reputations as play unfolds.

Testing this hypothesis requires an empirical proxy for the unobservable construct of reputation. One proxy for reputation is an image score that increases (decreases) when a person takes an action that is likely to be interpreted as favorable (unfavorable) by another person developing beliefs about the actor's future behavior. An image score provides a parsimonious cumulative measure of reputation based on the complete history of observed interactions. Image scores have been used in human experiments and have been useful in categorizing non-primate behavior (11-13, 39). We expect subjects' decisions to be more strongly associated with image scores (which we construct based on their partners' past decisions) for recordkeeping economies than for no recordkeeping economies. We thus predict that the positive correlation between partners' image scores and subject decisions will increase with recordkeeping and become more pronounced as the history of exchange unfolds.

We computed a trustee's cumulative image score with a specific investor in period $t$ based on all prior trustee return decisions with that investor-that is, returns up to and including
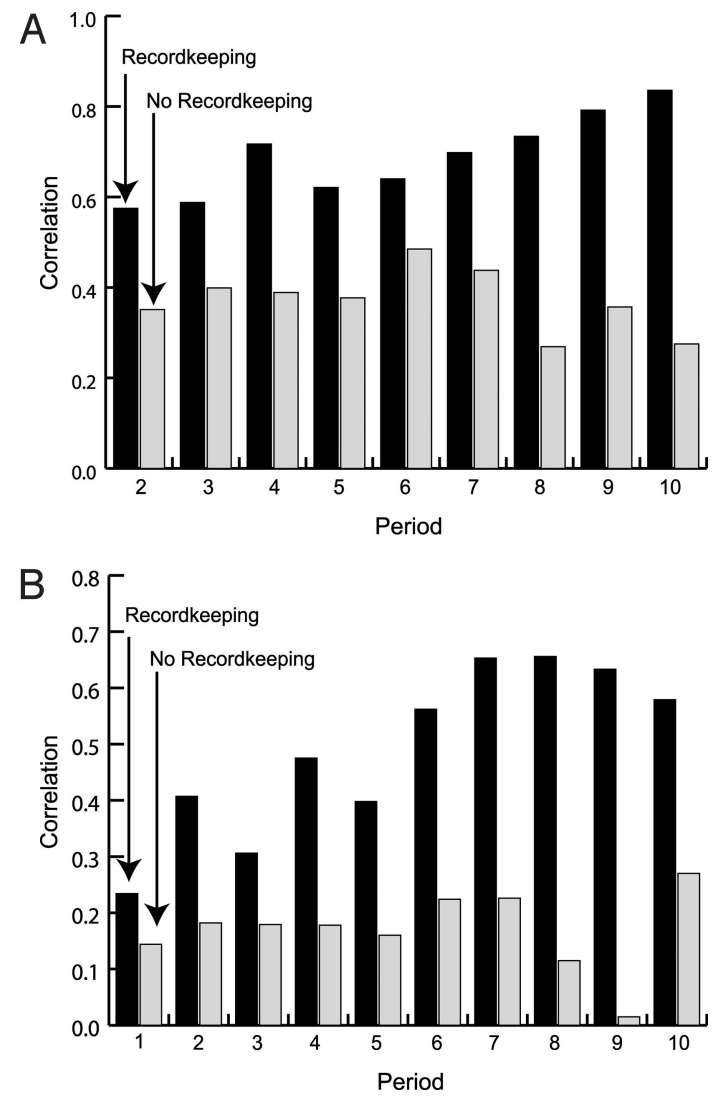

Fig. 1. Correlation between decisions and image scores across time. $(A)$ Mean session correlation of period $t$ Investment with period $t$ - 1 trustee image score. Shown is the average of session mean correlation between period $t$ investment and the period $t-1$ trustee image score for periods 2 through 10 for the recordkeeping and no recordkeeping economies. $(B)$ Mean session correlation of period $t$ ROE with period $t$ investor image score. Shown is the average of session mean correlation between period $t$ return on endowment and the period $t$ investor image score for periods 1 through 10 for the recordkeeping and no recordkeeping economies.

period $t$-1 (for more specific details on the calculation, see $S I$ ). The trustee's image score increases by 2 points ( 1 point) in any period where the trustee sends back an amount that exceeds investor's investment by a large (small) amount. Zero points are added to the trustee image score when the trustee has received nothing from the investor, and thus has no decision to make. The trustee's image score declines by 2 points (1 point) when the amount sent back by the trustee yields the investor a large (small) negative return in relation to the amount invested. We use image scores based on simple classifications of partner behavior to enhance consistency with prior studies of reputation in humans based on image scoring (11-13).

The mean correlations between investments and trustee image scores are more positive for the recordkeeping economies in every period, and this difference widens in later rounds (Fig. 1A). For example, the average of the mean (across 5 sessions) correlation for investments in periods $2-5$ and the one-period lagged trustee image score is 0.625 for the recordkeeping economy compared with 0.379 for the no recordkeeping economy. This difference is significant at $P=0.028$ (Mann-Whitney test, one-tailed). The mean correlation for the recordkeeping economy increases to 0.740 (from 0.625 ) in periods $6-10$ whereas the mean correlation for the no recordkeeping economy declines to 0.365 (from 0.379 ) in periods $6-10$. The difference in mean correlations between the recordkeeping and no recordkeeping 
economies for periods $6-10$ is significant at $P=0.004$ (MannWhitney test, one-tailed).

We computed changes in an investor's image score for a specific trustee based on amounts invested in a given period. An investor's cumulative image score increased by 2 points (1 point) in a period when a very large (large) investment was made. Modest investments of 5 lira resulted in no change whereas small (very small) investments resulted in image score declines of 1 point (2 points).

As with our results on trustee image scores, average contemporaneous correlations between investor image scores and the return on endowment (ROE) provided by the trustee are more positive for the recordkeeping economies than for the no recordkeeping economies in all 10 periods (Fig. $1 B$ ). ROE is a ratio equal to the investor's payoff from that trustee's dyad in that period relative to the investor's endowment for that specific trustee. The mean correlation between ROE and the investor's image score is 0.364 for the recordkeeping economies in periods $1-5$, and increases to 0.615 in periods $6-10$. The mean correlation for the no recordkeeping economies is lower than that of the recordkeeping economies in periods $1-5$ (0.169 versus 0.364$)$, and remains virtually unchanged in periods $6-10$. The difference in mean correlation between the recordkeeping and no recordkeeping economies is significant at $P$ less than or equal to 0.05 for both subperiods (Mann-Whitney test, one-tailed).

Recordkeeping Spontaneously Increases Investor-Trustee Coordination. One consequence of a link between reputation and decisions is that investors' and trustees' actions will become increasingly coordinated. That is, investors and trustees will come to be characterized by stronger mutually reinforcing behaviors when recordkeeping is possible. Investors will make larger investments in those trustees who have reciprocated their trust and trustees will more likely make equitable divisions after the investor has made a large investment. Coordinated reciprocal action aligns the behaviors of the investor and trustee and spontaneously increases convergence of each other's reputations. This coordination is consistent with balanced reciprocity where choice increasingly becomes conditioned on others' past behavior (40, 41). This hypothesis suggests that the correlation between investor and trustee image scores will increase through time and be more pronounced when recordkeeping is possible.

To test this hypothesis, we computed correlations between the investor's cumulative image score and the trustee's cumulative image score for every period in each multi-dyad economy (Fig. 2 ). The graph shows the mean (across sessions) correlation between investor and trustee image scores for the recordkeeping and no recordkeeping economies for each period. Image scores are calculated as described in the prior subsection. The mean correlation between investor and trustee image scores monotonically increases in every period for the recordkeeping economies but not for the no recordkeeping economies, for example, the no recordkeeping correlations in periods 8 and 10 are slightly lower than those in periods 7 and 9, respectively. The mean correlation for the recordkeeping economies is over twice as large as that of the no recordkeeping economies in both the 1-5 and 6-10 subperiods. Differences in mean correlations are significant at $P$ less than or equal to 0.05 (Mann-Whitney test, one-tailed).

Recordkeeping Promotes Reputation Formation Through Improved Memory. The causal basis for our hypotheses is that recordkeeping promotes reputation formation through better recall. As a result, subjects' choices in a recordkeeping economy incorporate a longer history of past exchanges. Our image score results do not allow us to identify these effects because a relation between image scores and subject choices could result from either the recent history of a partner's behavior or choices made in the

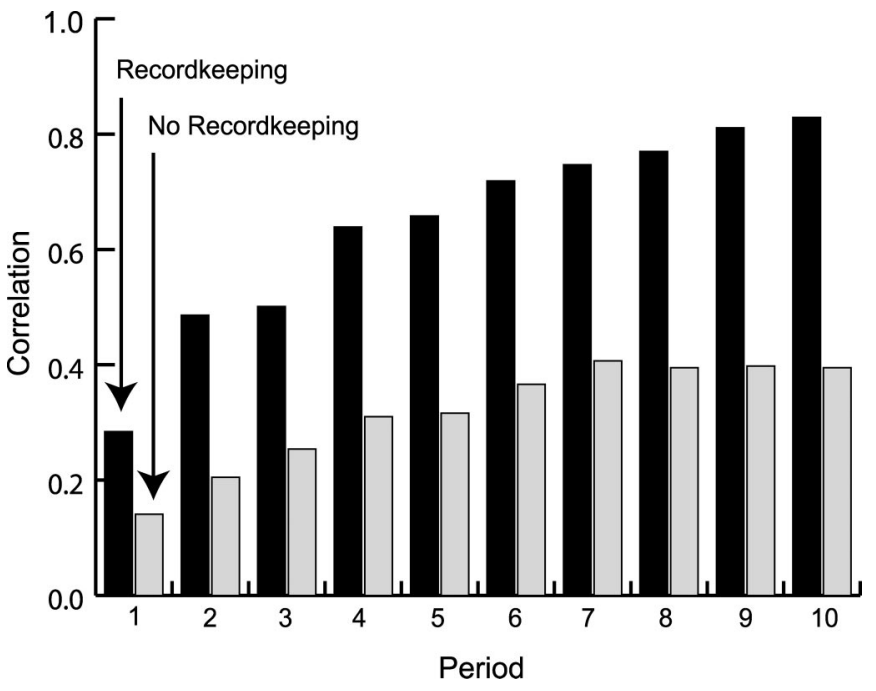

Fig. 2. Mean session contemporaneous correlation of investor and trustee image score. Shown is the average of session mean correlation between period $t$ investor image score and the period $t$ trustee image score for periods 1 through 10 for the recordkeeping and no recordkeeping economies.

more distant past. Thus, it is necessary to decompose image scores and examine the relation between score components and partners' behavior. We compare the correlations of subjects' choices with partners' future choices and expect that these correlations will remain more positive in later periods for the recordkeeping economies versus the no recordkeeping economies as the history of exchange unfolds.

A trustee's decision in an early period remains relevant to subsequent investor decisions longer in the recordkeeping economies than in the no recordkeeping economies (Fig. $3 A$ and $B$ ). The line beginning at the leftmost point in Fig. $3 A$ plots the mean correlation between period $1 \mathrm{ROE}$ and period $t+1$ investments $(t=1,2, \ldots 9)$ for the recordkeeping economies. The analogous line in Fig. $3 B$ applies to period 1 ROE for the no recordkeeping economies. The mean correlation between period $1 \mathrm{ROE}$ and period 2 investments equals 0.597 for the recordkeeping economies and 0.396 for the no recordkeeping economies, and both economies' period 1 ROE correlation with period 6 investments still exceeds 0.2 . However, by period 10 , the mean correlation between period $1 \mathrm{ROE}$ and investment for the no recordkeeping economies has fallen to 0.044 whereas the same correlation for the recordkeeping economies has remained strongly positive (equal to 0.349 ).

Moving rightward across both figures, the next line shows the mean correlations applicable to period 2 ROE, period 3 ROE, and so forth. Two patterns are apparent in these plots. First, the lines for the recordkeeping economies are flatter than those of the no recordkeeping economies, which suggests that a trustee's decisions continue to persistently affect investors' future choices. Second, successive lines for the recordkeeping economies tend to shift upward whereas no such effect is obvious for the no recordkeeping economies. This indicates that trustee decisions in a recordkeeping economy carry with them an expanding cumulative information set that is confirmed subsequently by investors' future behavior.

Investor decisions also remain correlated with future trustee $\mathrm{ROE}$ choices for a longer time in the recordkeeping economy, and this difference widens as time passes (Fig. $3 C$ and $D$ ). As was the case for trustee ROE decisions, the time-series correlation plots generally shift upward for later periods in the recordkeeping economies (Fig. 3C) whereas the plots for the no recordkeeping economies are generally $<0.2$ (Fig. 3D). The 

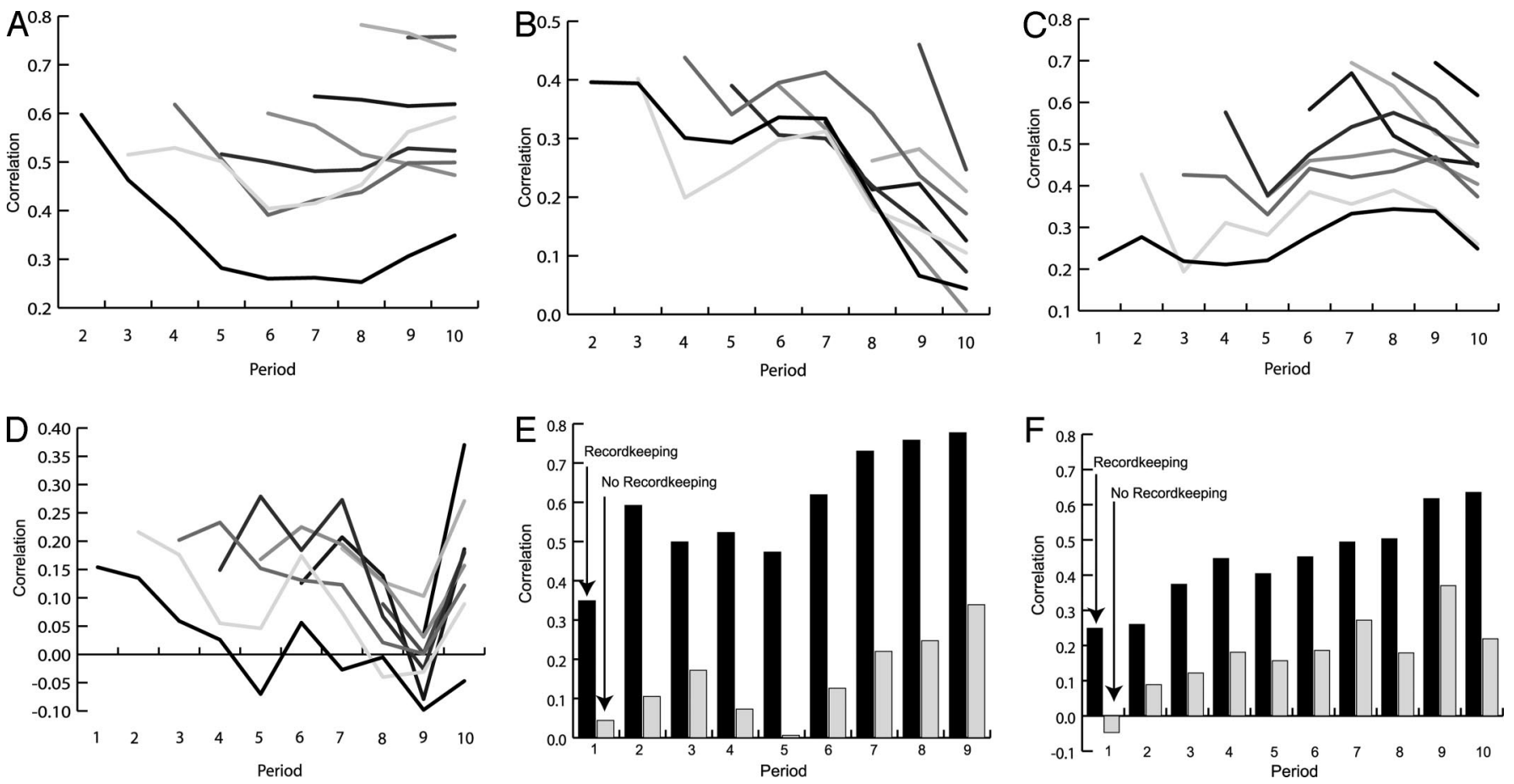

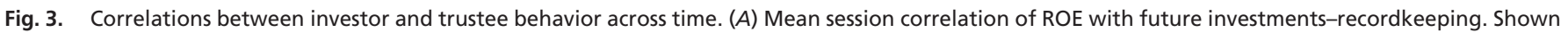

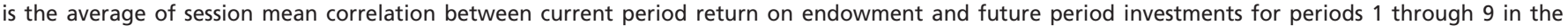

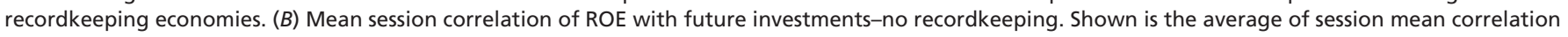

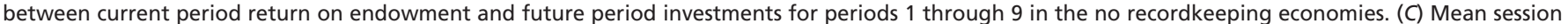

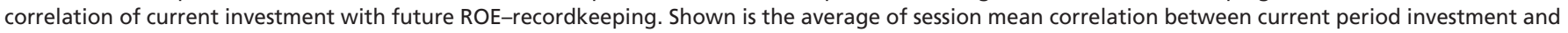

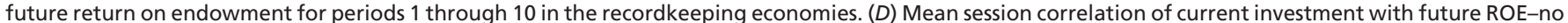

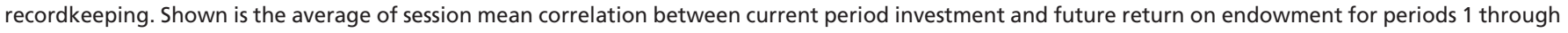

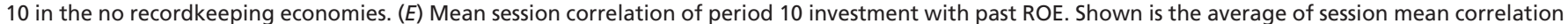

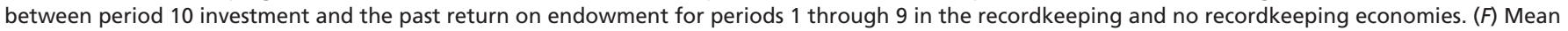

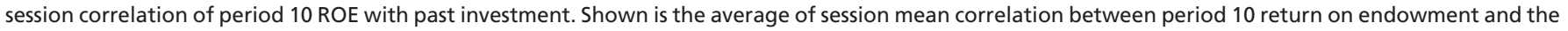
past investment for periods 1 through 10 in the recordkeeping and no recordkeeping economies.

discontinuity in Fig. $3 D$ for period 9 results from the behavior of two trustees who returned relatively low amounts after receiving large investments in period 9. These trustees may have guessed that the session was nearing an end; thus, the pattern could reflect end-of-game behavior.

The results in Fig. $3 A-D$ suggest that investor and trustee decisions carry with them a longer history of past exchanges in a recordkeeping economy. For investors, this is best illustrated by more positive mean correlations (across sessions) between investors' period 10 investments and past ROE's in the recordkeeping economies than in the no recordkeeping economies (Fig. $3 E$ ). The mean correlation for recordkeeping economies exceeds 0.3 for all periods, and is $>0.70$ for ROE in periods 7 through 9. In contrast, for no recordkeeping economies, the mean correlation between period 10 investment and past ROE exceeds 0.30 only for period 9 ROE. We compare the distributions of session-wide correlations in the 5 recordkeeping vs. 5 no recordkeeping economies, both in subperiods $1-5$ and subperiods 6-9. The differences in mean correlation are significant at $P$ less than or equal to 0.05 (one-tailed) in both subperiods.

A similar, but somewhat weaker, result holds when correlating period 10 ROE provided by the trustee with the investor's prior investments with that trustee (Fig. $3 F$ ). The mean correlation in the recordkeeping economies is more positive than the no recordkeeping economies in every period. A Mann-Whitney test rejects the null at $P$ less than or equal to 0.05 for investments in periods $6-10$.

Recordkeeping Beneficially Alters Economic History. We will first demonstrate that subjects' decisions are different in a record- keeping economy and then demonstrate that risk reduction benefits attach to these different decisions.

At the heart of reputation stories for reciprocity is that a decision maker discriminates in favor of those trading partners who have built a favorable reputation for reciprocity. In our experiment, discrimination by an investor will be reflected in investment levels that vary across trustees. A direct measure of investor discrimination is the spread between an investor's maximum and minimum investments in a given period. We expect the spread between maximum and minimum investments will be more positive with recordkeeping and any differences in investor spreads will be greater for later periods.

We compared the mean investment spread for the 5 recordkeeping and the 5 no recordkeeping economies for periods 1 through 5 and periods 6 through 10. Differences in mean spreads in periods $1-5$ are not statistically distinguishable for the recordkeeping and no recordkeeping economies. The mean spread in periods 6 through 10 equals 6.77 lira in the recordkeeping economies compared with 5.60 lira in the no recordkeeping economies; this difference is significantly different from zero at $P<0.05$ based on a one-tailed Mann-Whitney test (see first row of Table 1). The second row reveals that the significant mean difference in investment spreads for periods 6 through 10 is not the result of more frequent maximum investments. Instead, the rate at which investors make investments of zero lira increases over time to a greater degree in the recordkeeping economies (see third row in Table 1).

The frequency of "fair" return decisions by trustees is significantly higher in the recordkeeping economies in both subperi- 


\begin{tabular}{|c|c|c|c|c|c|c|}
\hline \multirow[b]{2}{*}{ Investor and trustee decisions } & \multicolumn{2}{|c|}{ Periods $1-5$} & \multicolumn{2}{|c|}{ Periods 6-10 } & \multicolumn{2}{|c|}{ Change $(+/-)$} \\
\hline & RK & No RK & RK & No RK & RK & No RK \\
\hline Mean of Economy's Average Investment Spread & 4.15 & 3.95 & 6.77 & $5.60^{* *}$ & +2.62 & +1.65 \\
\hline Mean of Economy's \% of Max Investments & 34.1 & $14.7^{*}$ & 34.7 & $18.9^{*}$ & +0.6 & +4.2 \\
\hline Mean of Economy's \% of Zero Investments & 9.8 & 12.3 & 26.9 & $21.0^{* *}$ & +17.1 & $+8.7^{* *}$ \\
\hline Mean of Economy's Trustee Fair Returns as $\%$ of Positive Investments & 25.8 & $10.0^{* *}$ & 33.9 & $15.4^{* *}$ & +8.1 & +5.4 \\
\hline
\end{tabular}

*, Significant at 0.01 level based on a one-tailed Mann-Whitney test.

**, Significant at 0.05 level based on a one-tailed Mann-Whitney test.

***, Significant at 0.10 level based on a one-tailed Mann-Whitney test.

ods (see the fourth row of Table 1). For present purposes, we define a "fair" return by the trustee as one where the amount received is split evenly between the investor and the trustee. Under this definition, at least $25 \%$ of all trustee return decisions are classified as fair in both subperiods for the recordkeeping economies compared with no $>17 \%$ in the no recordkeeping economies. The difference in the frequency of fair return decisions is significant in both subperiods $(P<0.05)$. Thus, the evidence in Table 1 demonstrates that the history of exchange decisions is different in a recordkeeping economy.

We next demonstrate that recordkeeping is associated with beneficial risk reduction. We focus on investor risk rather than trustee risk because as the first mover the investor incurs greater risk. Analysis of trustee risk is included in the SI. The risk to an investor in the trust game is the variation in the investor's return. We calculated this return as the ratio of the investor's total payoff relative to his/her initial endowment in every period for each dyad. The cross-sectional coefficient of variation of this ratio is our measure of investment risk present in a given type of economy (recordkeeping versus no recordkeeping) at a given point in time.

The recordkeeping economy's investment risk per unit of return is lower than that of the no recordkeeping economy after the first period (Fig. 4). The average of mean dyad-level coefficient of variation in periods $1-5$ is $0.324(0.383)$ for the recordkeeping (no recordkeeping) economies; this difference is not significant at $P$ less than or equal to 0.10 (see first row of

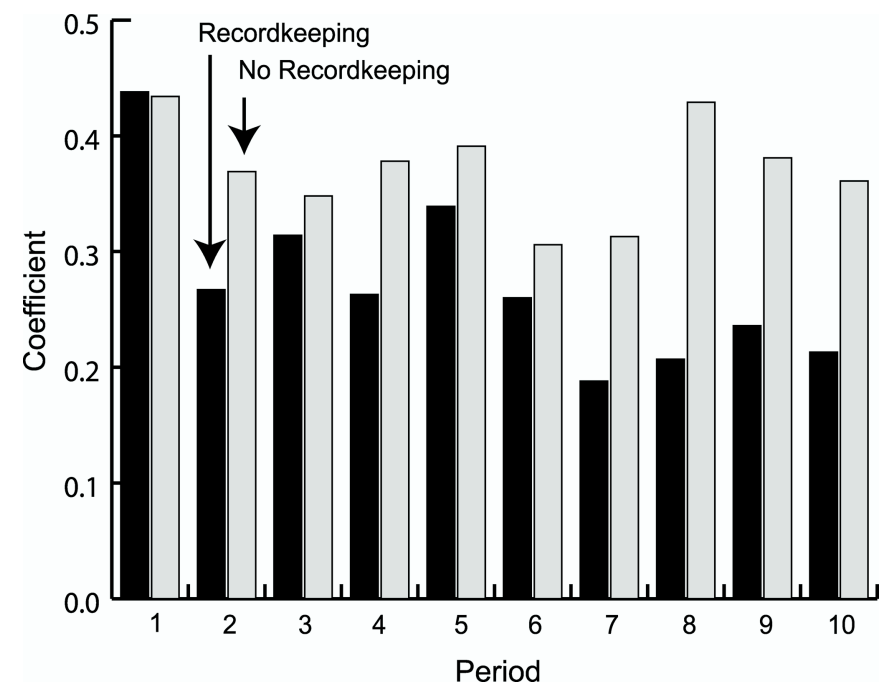

Fig. 4. Mean coefficient of variation for investor rates of return for a given type of economy (RK and No RK). Shown is the average of session mean coefficient of variation for period $t$ investor rates of return calculated at the dyad level for periods 1 through 10 for the recordkeeping and no recordkeeping economies.
Table 2). However, the difference in mean coefficient of variation in periods $6-10$ between the recordkeeping economies $(0.221)$ and the no recordkeeping economies $(0.358)$ is significant at $P=0.004$.

Because the coefficient of variation controls for mean returns, lower investor risk in the recordkeeping economies is not likely accompanied by a disproportionate sacrifice in the form of lower investor returns and dollar payoffs. Consistent with this, our data indicate that investors earn greater average rates of return in the recordkeeping economy $(18.7 \%)$ than in the no recordkeeping economy $(7.3 \%$ ) for periods 6-10 (see second row of Table 2). This difference is significant at $P<0.001$ (one-tailed).

\section{Discussion and Conclusions}

Experiments offer insight into how worlds are transformed by human institutions. We experimentally demonstrate that voluntary use of recordkeeping alters the character of reciprocal exchange. Recordkeeping enables better recall of past outcomes, promotes reputation formation, and encourages spontaneous coordination of economic decisions. The ultimate effect is that recordkeeping alters an economy's history and encourages exchange by reducing the risk of loss from transacting with strangers. Our findings are important because they support the hypothesis that the simple ability to record exchange externally can complement the brain's memory resources in consummating beneficial exchange with strangers. This implies that recordkeeping external to the brain, which is observed early in human history, may store the information necessary for the vast expansion of reciprocity and cooperation that characterizes modern human societies $(1-4,23-25)$. Further examination of this implication may prove fertile ground for future research. Agentbased modeling and other analytic modeling methods will likely be useful in unraveling the dynamic processes through which recordkeeping and other institutions coevolve with the economic development of society. Thus, future research on how recordkeeping (working in tandem with institutions to sanction and broadcast acts of deception) sustains and expands reciprocity promises a clearer understanding of why humans have built cooperative networks that dwarf those of other species in scale and complexity (11-14, 19, 29-31).

\section{Methods}

We conducted our experiment at the Center for Interuniversity Research and Analysis on Organization (CIRANO) in Montreal, Canada. CIRANO staff recruited subjects and ran 20 sessions ( 5 sessions for each experimental condition). Subjects (200) were recruited by CIRANO from a standard subject pool and remain anonymous to the authors. Each condition-specific experiment-session included 10 subjects, each of whom was randomly assigned to be either an investor or a trustee (with the restriction that each session contains 5 investors and 5 trustees). Further, each experiment-session included 10 trading periods. Subjects were not informed of the number of periods to mitigate end-game effects, although they were informed via recruiting materials that the experiment would last $\approx 2 \mathrm{~h}$. No experiment-session lasted longer than 90 min.

Subjects received and read written experiment instructions. Subjects then took a quiz to ensure sufficient understanding of experiment instructions. 
Table 2. Recordkeeping lessens exchange risk

\begin{tabular}{|c|c|c|c|c|c|c|}
\hline \multirow[b]{2}{*}{ Investor risk } & \multicolumn{2}{|c|}{ Periods $1-5$} & \multicolumn{2}{|c|}{ Periods $6-10$} & \multicolumn{2}{|c|}{ Change $(+/-)$} \\
\hline & RK & No RK & RK & No RK & RK & No RK \\
\hline $\begin{array}{l}\text { Average of period mean coefficient of variation } \\
\text { for dyad-level returns }\end{array}$ & 0.324 & 0.384 & 0.221 & $0.358^{*}$ & -0.103 & -0.026 \\
\hline Mean investor return, \% & 16.7 & 10.2 & 18.7 & $7.3^{*}$ & +2.0 & -2.9 \\
\hline
\end{tabular}

*, Significant at 0.01 level based on a one-tailed Mann-Whitney test. **, Significant at 0.05 level based on a one-tailed Mann-Whitney test. ***, Significant at 0.10 level based on a one-tailed Mann-Whitney test.

Subjects interacted anonymously over a local computer network facilitated by $z$-Tree (Zurich Toolbox for Readymade Economic Experiments) software (42). Each trading period began with investors deciding how much of 10 units of experiment-currency (i.e., lira) to invest in the paired trustee(s). In the multidyad conditions, investors had 5 separate endowments of 10 lira for each of the 5 trustees with whom the investor was paired. All investors' investment decisions were required before trustees received investment information. Similarly, all trustees' "return" decisions were required before both player types received feedback information. Investors received feedback information in the form of what each paired-trustee sent. Trustees received feedback information in the form of what was received from each paired-investor (i.e., the tripled investment amount). The next trading period began once all subjects confirmed they were finished reviewing feedback.

At the end of the tenth trading period, subjects completed a short questionnaire containing strategy-oriented and demographic questions. The lira earned for all periods was summed and converted to cash at a rate that varies by experimental condition to equalize the maximum possible payout per subject across exchange-conditions ( $C \$ 0.04$ per lira in the multi-dyad condition and $\mathrm{C} \$ 0.20$ per lira in the single dyad condition). Because each subject in the multi-dyad setting participates in 5 dyads each period, we set the conversion rate in the multi-dyad setting at $1 / 5$ that of the single-dyad setting.

In recordkeeping conditions, we provided a text-based electronic notebook to subjects. The notebook is a blank textbox, situated at the right side of the computer screen. The Textbox program recorded the contents of the

1. Gouldner A (1960) The norm of reciprocity: A preliminary statement. Am Soc Rev 25:161-178.

2. Alexander R (1987) The Biology of Moral Systems (Aldine Transaction, Piscataway, NJ).

3. Wilson E (2000) Sociobiology, The $25^{\text {th }}$ Anniversary Edition (Belknap Press of Harvard Univ Press, Cambridge, MA).

4. Brown D (1991) Human Universals (McGraw-Hill, New York).

5. Cosmides L, Tooby J (2005) The Handbook of Evolutionary Psychology, ed Buss D (Wiley, New York).

6. Trivers R (1971) The evolution of reciprocal altruism. Q Rev of Biol 46:35-57.

7. Axelrod R, Hamilton W (1981) The evolution of cooperation. Science 211:1390-1396.

8. Fehr E, Gachter S (2002) Altruistic punishment in humans. Nature 415:137-140.

9. de Quervain D, et al. (2004) The neural basis of altruistic punishment. Science 305:1254-1258.

10. Henrich J, et al. (2006) Costly punishment across human societies. Science 312:17671770 .

11. Nowak M, Sigmund K (1998) Evolution of indirect reciprocity by image scoring. Nature 393:573-577.

12. Wedekind C, Milinski M (2000) Cooperation through image scoring in humans. Science 288:850-852

13. Nowak M, Sigmund K (2005) Evolution of indirect reciprocity. Nature 437:1291-1298

14. Rockenbach B, Milinski M (2006) The efficient interaction of indirect reciprocity and costly punishment. Nature 444:718-723.

15. Gureck O, Irlenbusch B, Rockenbach B (2006) The competitive advantage of sanctioning institutions. Science 312:108-111.

16. Hoffman E, McCabe K, Smith V (1998) Behavioral foundations of reciprocity: Experimental economics and evolutionary psychology. Econ Inquiry 36:335-352.

17. McCabe K, Houser D, Ryan L, Smith V, Trouard T (2001) A functional imaging study of cooperation in two-person reciprocal exchange. Proc Natl Acad Sci USA 98:1183211835.

18. McCabe K, Rigdon M, Smith V (2003) Positive reciprocity and intentions in trust games. $J$ Econ Behav Organ 52:267-275.

19. Dunbar R (1998) The social brain hypothesis. Evol Anthropol 6:178-190.

20. U.S. Securities and Exchange Commission (2006) Form 10-K Annual Report of eBay Inc for 12/31/2006 year. Available at http://www.sec.gov. Accessed December 1, 2008.

21. Dewally $M$, Ederington $L$ (2006) Reputation, certification, warranties, and information as remedies for seller-buyer information asymmetries: Lessons from the online comic book market. J of Business 79:693-730. textbox every $5 \mathrm{~s}$ for the length of the experiment-session, providing data regarding the timing, content, and extent of recordkeeping engaged in by individual subjects. This program is the only method of personal external recordkeeping available to subjects. Subjects did not have access to paper and pencils, nor could they use computer programs other than z-Tree and Textbox (the latter available for only those subjects in the recordkeeping condition).

ACKNOWLEDGMENTS. We thank Ernst Fehr, Joe Henrich, Dan Houser, and Vernon Smith for helpful conversations and suggestions and the staff at CIRANO in Montreal who helped in running our experiment. We benefited from comments and suggestions by audience members at the meetings of the American Accounting Association, Economic Science Association, and the Human Behavior and Evolution Society. We also benefited from interactions at workshops presented at the 2006 MiniConference on the Foundations of Accounting at the Goizueta Business School of Emory University, the Emory University Anthropology Department, the Boston Accounting Research Colloquium, University of Arizona, City University of Hong Kong, City University of New York-Baruch, George Mason University (Accounting Group), George Washington University, Interdisciplinary Center for Economic Studies at George Mason University, University of lowa, London School of Economics, Michigan State University, University of Minnesota, Norwegian School of Economics, University of Notre Dame, Queen's University (Canada), Southern Methodist University, Temple University, Texas A\&M University, University of Texas-Dallas, Tilburg University, and Tulane University. This work was supported by the Goizueta School at Emory University and the Carlson School at the University of Minnesota.

22. Resnick P, Zeckhauser R, Swanson J, Lockwood K (2006) The value of reputation on eBay: A controlled experiment. Exp Econ 9:79-101.

23. Donald M (1991) Origins of the Modern Mind: Three Stages in the Evolution of Culture and Cognition (Harvard Univ Press, Cambridge, MA).

24. Schmandt-Besserat D (1992) Before Writing, Vol. 1 (Univ of Texas Press, Austin, TX).

25. Nissen H, Damerow P, Englund R (1993) Archaic Bookkeeping: Writing and Techniques of Economic Administration in the Ancient Near East (Univ of Chicago Press, Chicago).

26. Malinowski B (1984) Argonauts of the Western Pacific (Waveland Press, Long Grove IL), reissue.

27. Littleton AC (1933) Accounting Evolution to 1900 (Russell \& Russell, New York)

28. Sunder S (1997) Theory of Accounting and Control (South-Western College Publishing, Cincinnati)

29. North D (2005) Understanding the Process of Economic Change (Princeton Univ Press, Princeton).

30. Smith V (2003) Constructivist and ecological rationality in economics. Am Econ Rev 93:465-508.

31. Henrich J (2006) Cooperation, punishment, and the evolution of human institutions. Science 312:60-61.

32. Smith A (1976) The Wealth of Nations (Univ of Chicago Press, Chicago), reissue.

33. Basu S, Waymire G (2006) Recordkeeping and human evolution. Accounting Horizons 20:201-229

34. Berg J, Dickhaut J, McCabe K (1995) Trust, reciprocity, and social history. Games and Econ Behavior 10:122-142.

35. Fehr E, Kirchsteiger G, Riedl A (1998) Gift exchange and reciprocity in competitive experimental markets. Euro Econ Rev 42:1-34

36. King-Casas B, et al. (2005) Getting to know you: Reputation and trust in a two-person economic exchange. Science 308:78-83.

37. Croson R, Buchan N (1999) Gender and culture: International experimental evidence from trust games. Am Econ Rev 89:386-391.

38. Glaeser E, Laibson E, Scheinkman J, Soutter C (2000) Measuring trust. Q J of Econ 155:811-846

39. Bshary R, Grutter A (2006) Image scoring and cooperation in a cleaner fish mutualism. Nature 441:975-978.

40. Mauss M (1950) The Gift (Norton, London), trans Halls W (1990).

41. Sahlins M (1972) Stone Age Economics (Aldine De Gruyter, New York).

42. Fischbacher U (2007) z-Tree: Zurich toolbox for ready-made economic experiments. Exp Econ 10:171-178. 